\title{
Remission of diabetes mellitus after treatment with pioglitazone
}

\author{
SS Jayasinghe ${ }^{1}$, LM Hettihewa ${ }^{2}$, SW Gunasekara ${ }^{1}$, S Palangasinghe ${ }^{1}$, KG Imendra ${ }^{3}$, TP \\ Weerarathna ${ }^{4}$ \\ ${ }^{1}$ Department of Pharmacology, ${ }^{2}$ Molecular Science and Biomedical Unit, ${ }^{3}$ Department of Physiology, \\ ${ }^{4}$ Department of Medicine, Faculty of Medicine, University of Ruhuna, Galle.
}

\section{Introduction}

Type 2 diabetes is a complex disease that involves insulin secretion abnormalities and defects in the action of insulin on its target tissues. This chronic metabolic disorder is associated with high mortality and morbidity from long-term microvascular and macrovascular complications [1]. Thiazolidinediones (pioglitazone, rosiglitazone, and troglitazone) are synthetic peroxisomes proliferated receptor-ã agonists that decrease insulin resistance, may also have direct beneficial effects on pancreatic â cells [2].
Previous reports shows that decrease in fasting plasma insulin with pioglitazone associated with the improvement of insulin sensitivity [2]. Treatment with pioglitazone was associated with beneficial effects on blood lipid levels as well. Here we present a patient who got a remission of type 2 diabetes mellitus after 2 months of pioglitazone therapy (15 mg). 


\section{Method}

Fifty-six year old female, diagnosed having type 2 diabetes with initial $218.2 \mathrm{mg} / \mathrm{dL}$ of fasting blood glucose, was recruited to our kinetic study in improvement of insulin resistance with pioglitazone. She was followed up for the effects of pioglitazone on body weight (BW), body mass index (BMI), blood pressure (BP), fasting blood sugar (FBS), lipid profile and fasting insulin (FI). Before the treatment, BMI was $23.63 \mathrm{~kg} / \mathrm{m}^{2}$, BP - 120/80 mmHg, total cholesterol (TC) - 260.64 mg/dl, triglyceride (TG) - $122.71 \mathrm{mg} / \mathrm{dL}$, HDLcholesterol (HDL) - $69.76 \mathrm{mg} / \mathrm{dL}$, LDLcholesterol (LDL) $-166.34 \mathrm{mg} / \mathrm{dL}$ and FI was $\mathrm{mU} / \mathrm{L}$. She was on pioglitazone $15 \mathrm{mg} /$ daily with dietary control and followed up for six months at monthly intervals.

\section{Results}

There was a reduction in FBS from $218.2 \mathrm{mg} / \mathrm{dL}$ to $185.7 \mathrm{mg} / \mathrm{dL}$ and it was $108.36 \mathrm{mg} / \mathrm{dL}$ at the end of the second month. Decision was made to withdraw the pioglitazone therapy due to normalization of glucose levels and advised to continue with proper dietary control. Changes in her FBS and FI during the follow up period of six months are given in figures 1 and 2. Her plasma insulin level was $31 \mathrm{mU} / \mathrm{L}$ at baseline and declined to $13 \mathrm{mU} / \mathrm{L}$ after one month of pioglitazone. FI further declined to $11 \mathrm{mU} / \mathrm{L}$ at third month. It again increased to14 $\mathrm{mU} / \mathrm{L}$ at the end of six months.

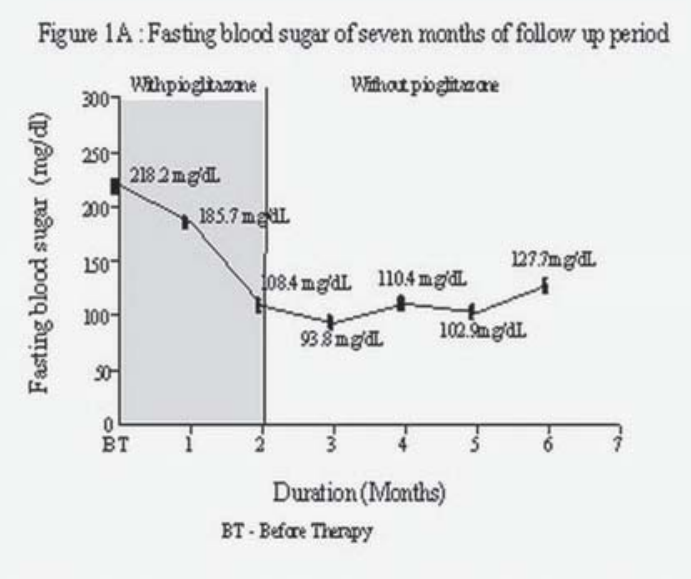

Figure 1
Figure 1B : Fasting insulin of seven months of follow up period

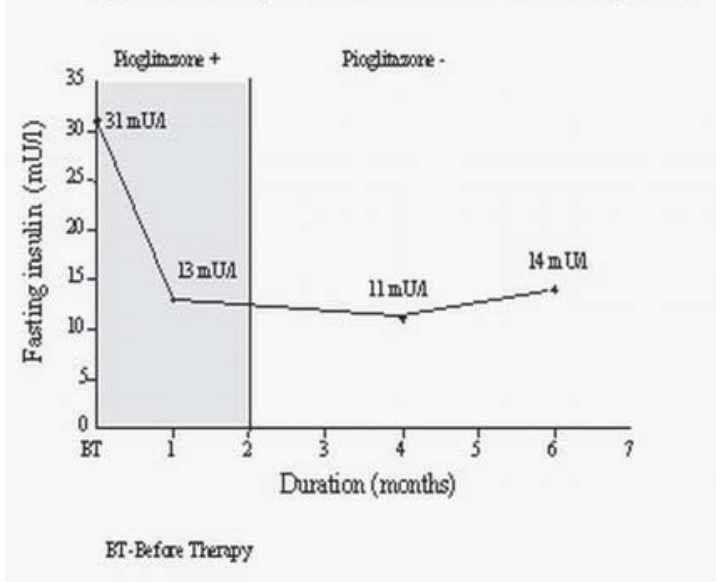

Figure 2

\section{Discussion}

People with diabetes have a higher risk of cardiovascular disease [1]. For all cardiovascular syndromes, the mortality is virtually doubled in patients with diabetes [3]. Large clinical trials have provided clear evidence of the reduction in cardiovascular risk that can be achieved by treating hyperglycaemia as well as traditional risk factors such as hypertension and hyperlipidaemia [3]. History of our patient shows blood glucose normalisation within two months of pioglitazone monotherapy. The patient was managed only with dietary control for the next four months. In the sixth month, her FBS came up to $127.72 \mathrm{mg} / \mathrm{dL}$. FI was $31 \mathrm{mU} / \mathrm{L}$ before the commencement of the treatment and declined to $13 \mathrm{mU} / \mathrm{L}$ after 2 months and further to $11 \mathrm{mU} / \mathrm{L}$ at the end of the third month. This evidence shows that decrease in fasting plasma insulin levels correlate with effects of pioglitazone.

History of this patient suggests that pioglitazone is effective in improving insulin sensitivity and good glycaemic control. Normoglycaemic period of two months in the absence of drugs further indicates that insulin sensitivity persisted even in the absence of therapy. Her fasting blood sugar raise at the sixth month up to $127.72 \mathrm{mg} / \mathrm{dL}$ and FI level has risen to $14 \mathrm{mU} / \mathrm{L}$. In this patient TC and LDL levels started to decline with the treatment and also through the follow up period. HDL level rose initially with the treatment, but again declined after cessation of the therapy. Though TG level reduced 


\section{Case reports}

to $106.14 \mathrm{mg} / \mathrm{dL}$ at the end of first month it increased throughout the follow up period.

Therefore early intervention with the agents targeting insulin resistance and increase in secretors that are associated with pancreatic $\beta$ cell failure, can delay progression or even prevent type 2 diabetes for relatively long periods of time, affords great promise in addressing the global epidemic of diabetes.

\section{References}

1. Richard JW, Gerard TC, Gerald FW. Mechanisms, significance and treatment of vascular dysfunction in type 2 diabetes mellitus. Focus on lipid-regulating therapy. Drugs 2005; 65: 31-74.
2. Helmut W, Georg L. Potential Role of Oral Thiazolidinedione therapy in preserving $\beta$-cell function in type 2 diabetes mellitus. Drugs 2005; 65: 1-13.

3. Kirsten AM, Sheila MW, Jim IM et al. Diagnosing insulin resistance in the general population. Diabetes Care 2001; 24: 460-4.

4. Report of the Expert Committee on the diagnosis and classification of Diabetes Mellitus. Diabetes Care 1997; 20: 1183-97.

5. Juan FA, Susana P, Jose TR, et al. Diagnosing insulin resistance by simple quantitative methods in subjects with normal glucose metabolism. Diabetes Care 2003; 29: 3320-5. 